Article

\title{
A Greener HPTLC Approach for the Determination of $\beta$-Carotene in Traditional and Ultrasound-Based Extracts of Different Fractions of Daucus carota (L.), Ipomea batatas (L.), and Commercial Formulation
}

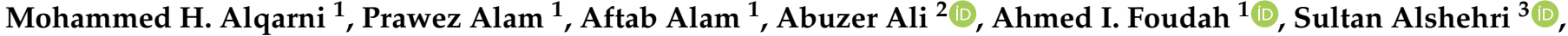 \\ Mohammed M. Ghoneim ${ }^{4}$ (D) and Faiyaz Shakeel ${ }^{3, *(D)}$
}

1 Department of Pharmacognosy, College of Pharmacy, Prince Sattam Bin Abdulaziz University, P.O. Box 173, Al-Kharj 11942, Saudi Arabia; m.alqarni@psau.edu.sa (M.H.A.); prawez_pharma@yahoo.com (P.A.); a.alam@psau.edu.sa (A.A.); a.foudah@psau.edu.sa (A.I.F.)

2 Department of Pharmacognosy, College of Pharmacy, Taif University, Taif 21944, Saudi Arabia; abuali@tu.edu.sa

3 Department of Pharmaceutics, College of Pharmacy, King Saud University, P.O. Box 2457, Riyadh 11451, Saudi Arabia; salshehri1@ksu.edu.sa

4 Department of Pharmacy Practice, College of Pharmacy, AlMaarefa University, Ad Diriyah 13713, Saudi Arabia; mghoneim@mcst.edu.sa

Citation: Alqarni, M.H.; Alam, P.; Alam, A.; Ali, A.; Foudah, A.I.; Alshehri, S.; Ghoneim, M.M.; Shakeel, F. A Greener HPTLC Approach for the Determination of $\beta$-Carotene in Traditional and Ultrasound-Based Extracts of Different Fractions of Daucus carota (L.), Ipomea batatas (L.), and Commercial Formulation. Agronomy 2021, 11, 2443. https:// doi.org/10.3390/agronomy11122443

Academic Editors: Mercedes Vazquez Espinosa and Gerardo Fernández Barbero

Received: 7 November 2021 Accepted: 29 November 2021 Published: 30 November 2021

Publisher's Note: MDPI stays neutral with regard to jurisdictional claims in published maps and institutional affiliations.

Copyright: () 2021 by the authors. Licensee MDPI, Basel, Switzerland. This article is an open access article distributed under the terms and conditions of the Creative Commons Attribution (CC BY) license (https:// creativecommons.org/licenses/by/ $4.0 /)$.

\begin{abstract}
Various analytical approaches for determining $\beta$-carotene in vegetable crops and commercial dosage forms have been documented. However, neither the qualitative nor quantitative environmental safety and greener aspects of the literature analytical methodologies of $\beta$-carotene analysis have been assessed. As a result, the goal of this research is to develop and validate a reversed-phase "high-performance thin-layer chromatography (HPTLC)" approach for determining $\beta$-carotene in traditional (TE) and ultrasound-assisted (UBE) extracts of different fractions of Daucus carota $(\mathrm{L}$.$) , Ipomea batatas (\mathrm{L}$.$) , and commercial formulation. The greener mobile phase for \beta$-carotene analysis was a ternary mixture of ethanol, cyclohexane, and ammonia $\left(95: 2.5: 2.5, v v v^{-1}\right)$. The detection of $\beta$-carotene was done at a wavelength of $459 \mathrm{~nm}$. In the $25-1000 \mathrm{ng}^{\text {band }}{ }^{-1}$ range, the greener reversed-phase HPTLC approach was linear. Other validation factors for $\beta$-carotene analysis, including as accuracy, precision, robustness, and sensitivity, were likewise dependable. The contents of $\beta$-carotene were found to be maximum in hexane: acetone (50:50\%) fractions of TE and UBE of $D$. carota and I. batatas compared to their acetone and hexane fractions. The amount of $\beta$-carotene in hexane: acetone (50:50\%) portions of TE of D. carota, I. batatas and commercial formulation A was estimated to be $10.32,3.73$, and 6.73 percent $w w^{-1}$, respectively. However, the amount of $\beta$-carotene in hexane: acetone (50:50\%) portions of UBE of D. carota, I. batatas and commercial formulation A was estimated to be $11.03,4.43$, and 6.89 percent $w w^{-1}$, respectively. The greenness scale for the proposed HPTLC strategy was calculated as 0.81 using the "analytical GREEnness (AGREE)" method, indicating that the proposed HPTLC methodology has good greenness. The UBE approach for extracting $\beta$-carotene outperformed the TE procedure. These results indicated that the greener reversed-phase HPTLC approach can be utilized for the determination of $\beta$-carotene in different vegetable crops, plant-based phytopharmaceuticals, and commercial products. In addition, this approach is also safe and sustainable due to the utilization of a greener mobile phase compared to the toxic mobile phases utilized in literature analytical approaches of $\beta$-carotene estimation.
\end{abstract}

Keywords: analytical GREEnness (AGREE); $\beta$-carotene; greener high-performance thin-layer chromatography (HPTLC); Daucus carota; Ipomea batatas; ultrasound extraction; validation; vegetable crops 


\section{Introduction}

Carotenes are pigments (yellow-orange, molecular formula: $\mathrm{C}_{40} \mathrm{H}_{56}$ ), abundantly found in the vegetable plants. The two principal isomers found in plants are $\alpha$-carotene and $\beta$-carotene [1]. The $\beta$-carotene is the most prevalent form of carotene in plants and is an essential nutritional resource and a precursor of vitamin A in humans [1,2]. Carotenes have a wide spectrum of biological activity and animal health benefits, making them a promising substance for the pharmaceutical, food, and cosmetics sectors. Kim (2016) examined the most recent research on carotenes and their biological and pharmacological effects [3].

The root of Daucus carota L. (family: Apiaceae), commonly referred to as carrot, is an essential vegetable source of bioactive chemicals in human and animal diets, as well as having remarkable economic significance as the world's most plentiful food crop [4,5]. Dietary fiber, $\alpha$ - and $\beta$-carotene (vitamin A precursors), ascorbic acid, thiamine, riboflavin, niacin, carbohydrates, and a high potassium content are all found in the root of D. carota [6]. In addition to carotenoids and above-mentioned nutrients, carrots also contain anthocyanins, which enhance their nutritional value [5]. It is a very good source of antioxidant $[7,8]$ along with anti-diabetic, anti-inflammatory, cardioprotective activities, hepatoprotective, nephroprotection, and anti-atherogenic activities $[9,10]$.

The roots of Ipomoea batatas L. Lam. (family: Convolvulaceae), widely known as the sweet potato, have long been used as an energy source and a valuable source of sustenance for humans and animals. Sweet potato is the world's sixth most abundant food crop [11], and it continues to be of incredible economic worth. Dietary fiber, carbohydrates, vitamin A (as $\beta$-carotene), vitamin B6, vitamin C, copper, manganese, potassium, and iron are all found in the root of I. batatas [12]. Sweet potato also had some other carotenoids, including $\beta$-carotene-5,8,5', $8^{\prime}$-diepoxide, $\beta$-carotene-5,8-epoxide, and ipomoeaxanthin $\mathrm{A}$, in addition to $\beta$-carotene [13]. Furthermore, it had great potential for bioenergy production $[12,13]$. Sweet potato antioxidant capacities have recently been studied due to the presence of phenolics, flavonoids, $\beta$-carotene, anthocyanins, and caffeoylquinic acid derivatives $[14,15]$ Its medical usage has been documented in several studies, particularly its antiviral and antidiabetic characteristics $[16,17]$.

The $\beta$-carotene is the main biomarker compound of these crops and hence its qualitative and quantitative standardization is necessary. Several analytical procedures are used to determine $\beta$-carotene in a range of plant-based products for this purpose. Fewer ultraviolet (UV)-based spectrometry approaches are utilized for $\beta$-carotene estimation either alone or in combination with other phytopharmaceuticals in various vegetable crops [18,19]. Various "high-performance liquid chromatography (HPLC)" approaches are also used to determine $\beta$-carotene either alone or in combination with other phytopharmaceuticals in various vegetable crops, nutritional supplements, and commercial formulations [20-28]. Several "high-performance thin-layer chromatography (HPTLC)" approaches are also used to determine $\beta$-carotene either alone or in combination with other phytopharmaceuticals in various vegetable crops, nutritional supplements, and commercial formulations [29-34]. A gas-chromatography mass-spectrometry approach was also applied to identify various carotenoid contents including $\alpha$-, and $\beta$-carotene of minimally processed carrots stored at different temperatures [35]. Some other analytical approaches such as fluorimetry, Fourier transforms-Raman spectroscopy, attenuated total reflectance-infrared, and near infra-red spectrometry approaches have also been applied in the determination of $\beta$-carotene either alone or in combination with other natural compounds in different food samples [36,37]. We noticed that the safety and greener characteristics of literature analytical approaches to $\beta$-carotene estimates were not appraised after reviewing literature analytical approaches. Greener HPTLC approaches present several merits over other liquid chromatograpy-based approaches [38-41]. As a result, in this investigation, the greener reversed-phase HPTLC technique for determining $\beta$-carotene was chosen. Various strategies for evaluating the greenness of various analytical procedures have been presented [40-45]; while only the "analytical GREEnness (AGREE)" technique applies all twelve principles/components of "green analytical chemistry (GAC)" for greenness evaluation [44]. Therefore, the "AGREE 
metric approach" was utilized for the greenness assessment of the greener reversed-phase HPTLC approach [44]. The current study involves the development and validation of a rapid, sensitive, and greener reversed-phase HPTLC approach for determining $\beta$-carotene in its pure form, traditional extraction (TE) and ultrasound-based extraction (UBE) of different fractions of $D$. carota and I. batatas, as well as commercial formulation, based on these hypotheses. The "International Council for Harmonization (ICH)" Q2-(R1) guidelines [46] were used to validate the greener reversed-phase HPTLC approach for determining $\beta$-carotene.

\section{Materials and Methods}

\subsection{Sampling}

The fresh roots of D. carota (carrots) and I. batatas (sweets potato) were purchased in a local supermarket of Al-Kharj, Saudi Arabia, which were provided by the local cultivars of Al-kharj, Central region of Saudi Arabia. The commercial soft gelatin capsules of $\beta$-carotene i.e., formulation A were obtained from a pharmacy shop in "Al-Kharj, Saudi Arabia".

\subsection{Chemicals and Reagents}

The working standard of $\beta$-carotene (purity: 98.7\%) was obtained from "Sigma Aldrich (St. Louis, MO, USA)". Chromatography-grade solvents such as ethanol (EtOH) and cyclohexane $(\mathrm{CY})$ were procured from "E-Merck (Darmstadt, Germany)". Analytical grade solvents for the TE and UBE, including acetone, hexane, and ammonia (A) were procured from "E-Merck, Darmstadt, Germany".

\subsection{Chromatography and Instrumentation}

The determination of $\beta$-carotene in its pure form, TE and UBE of various fractions of carrot, sweet potato, and marketed formulation A (soft gelatin capsule) was conducted using "HPTLC CAMAG TLC system (CAMAG, Muttenz, Switzerland)". The reversedphase HPTLC analysis of $\beta$-carotene was performed via " $10 \times 20 \mathrm{~cm}$ glass plates pre-coated with RP silica gel 60 F254S plates (E-Merck, Darmstadt, Germany)". The samples were applied as the $6 \mathrm{~mm}$ bands using a "CAMAG Automatic TLC Sampler 4 (ATS4) Sample Applicator (CAMAG, Geneva, Switzerland)". The "CAMAG microliter Syringe (Hamilton, Bonaduz, Switzerland)" was connected to the sample applicator. The application rate for determining $\beta$-carotene was kept constant at $150 \mathrm{~nL} \mathrm{~s}^{-1}$. Under linear ascending mode, the reversed-phase silica gel TLC plates were established in a "CAMAG automated developing chamber 2 (ADC2) (CAMAG, Muttenz, Switzerland)" with a distance of $80 \mathrm{~mm}$. The ternary combination of EtOH-CY-A (95:2.5:2.5, $\left.v v v^{-1}\right)$ was used as the greener mobile phase. The development chamber was saturated previously with the vapors of $\mathrm{EtOH}-$ CY-A $\left(95: 2.5: 2.5, v v v^{-1}\right)$ for $30 \mathrm{~min}$ at $22{ }^{\circ} \mathrm{C}$. The detection of $\beta$-carotene was done at a wavelength of $459 \mathrm{~nm}$. The slit dimensions (band length $\times$ width) and scanning rate were maintained constant at $4 \times 0.45 \mathrm{~mm}$ and $20 \mathrm{~mm} \mathrm{~s}^{-1}$, respectively. Each estimation was conducted in three or six replicates. The software applied was "WinCAT's (version 1.4.3.6336, CAMAG, Muttenz, Switzerland)". A schematic picture for the proposed HPTLC system with method development is presented in Figure 1.

\section{4. $\beta$-Carotene Calibration Curve and Quality Control (QC) Samples}

To obtain a stock solution of $100 \mu \mathrm{g} \mathrm{mL} \mathrm{L}^{-1}$, the required amount of $\beta$-carotene $(10 \mathrm{mg})$ was dissolved in $100 \mathrm{~mL}$ of EtOH-CY-A (95:2.5:2.5, $\left.v v v^{-1}\right)$. To acquire $\beta$-carotene concentrations in the $25-1000 \mathrm{ng}_{\text {band }}{ }^{-1}$ range, several volumes of this stock solution were diluted further using the EtOH-CY-A (95:2.5:2.5, $\left.v v v^{-1}\right)$ greener mobile phase. The resulting $\beta$-carotene solutions were spotted onto reversed-phase silica gel TLC plates in various concentrations. Using the greener reversed-phase HPTLC approach, the HPTLC response for $\beta$-carotene was noted at each $\beta$-carotene concentration. Plotting the $\beta$-carotene concentrations against the recorded chromatographic response yielded the $\beta$-carotene calibration curve. In addition, three distinct QC samples were acquired separately for vali- 
dation evaluation of the greener reversed-phase HPTLC approach, including low QC (LQC; $100 \mathrm{ng} \mathrm{band}^{-1}$ ), middle QC (MQC; $400 \mathrm{ng}$ band $^{-1}$ ), and high QC (HQC; $1000 \mathrm{ng}^{\text {band }}{ }^{-1}$ ).

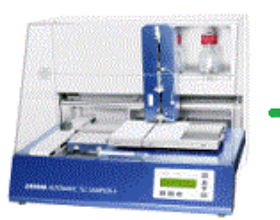

Sample applicator

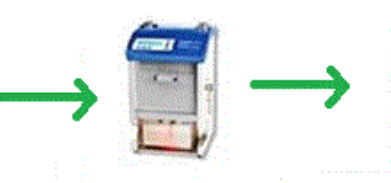

Chromatographic development

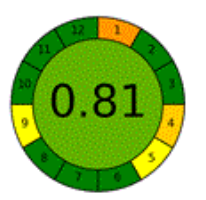

AGREE score

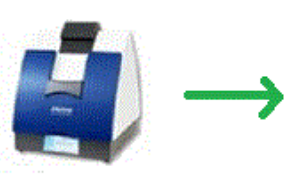

UV-Vis detection

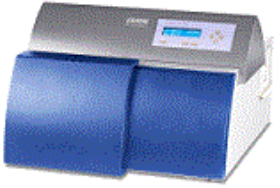

TLC scanner

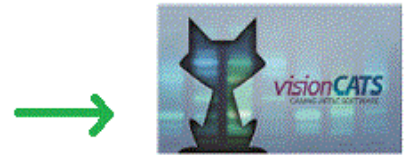

visionCATS software

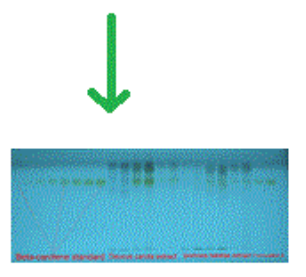

Developed plate

Figure 1. A schematic diagram for the proposed "high-performance thin-layer chromatography (HPTLC)" instrument along with method development for the determination of $\beta$-carotene.

\subsection{Sample Processing for the Determination of $\beta$-Carotene in TE of Carrots, Sweet Potato, and Commercial Formulation A}

The uniform size of carrots and sweet potatoes were made using a knife and then washed with tap water several times. After $10 \mathrm{~min}$ of cutting, these samples were blended into small pieces using a blender, and put into a "Lyophilizer (Freezone ${ }^{\circledR} 2.5$ model 76530, Labconco Corp., Kansas, MO, USA)", for $40 \mathrm{~h}$ and then stored at $20^{\circ} \mathrm{C}$. Approximately $10 \mathrm{~g}$ of each powder was separately extracted with $100 \mathrm{~mL}$ of hexane, hexane: acetone (50:50\%), and acetone. After extraction, $10 \mathrm{mg} / \mathrm{mL}$ solution of each sample was separately prepared in the hexane and acetone (1:1) solvent for analysis of the presence of $\beta$-carotene utilizing the greener analytical approach.

A precisely weighed $4.0 \mathrm{mg}$ of the contents from the soft gelatin capsules were dissolved in $10 \mathrm{~mL}$ of hexane: acetone (50:50 percent) for the measurement of $\beta$-carotene in commercial formulation A (soft gelatin capsules). Under lowered pressure, the solvent was evaporated. To reconstitute the remaining residue,. $10 \mathrm{~mL}$ hexane: acetone (50:50 percent) was used. This solution was utilized for $\beta$-carotene estimation utilizing the greener reversed-phase HPTLC approach.

\subsection{Sample Processing for the Determination of $\beta$-Carotene in UBE of Carrots, Sweet Potato, and Commercial Formulation A}

The uniform size of carrots and sweet potatoes were made using A knife and then washed with tap water several times. After $10 \mathrm{~min}$ of cutting, these samples were blended into small pieces using a blender, and put into a "Lyophilizer (Freezone ${ }^{\circledR} 2.5$ model 76530, Labconco Corp., Kansas, MO, USA)", for $40 \mathrm{~h}$ and then stored at $20^{\circ} \mathrm{C}$. The UBE was carried out utilizing ultrasonic vibrations with the help of the "Bransonic series (Model CPX5800H-E; Princeton, NJ, USA)". Approximately $10 \mathrm{~g}$ of each powder was separately extracted with $100 \mathrm{~mL}$ of hexane, hexane: acetone (50:50\%), and acetone using the above apparatus. The organic solvents were evaporated separately utilizing a rotary vacuum evaporator. The residue obtained from each fraction was dissolved in $50 \mathrm{~mL}$ of hexane, hexane: acetone $(50: 50 \%)$, or acetone separately in a volumetric flask. Each UBE was ultrasonicated at $50{ }^{\circ} \mathrm{C}$ for about one hour. The obtained solutions were utilized for the determination of $\beta$-carotene in UBE of different fractions of carrots and sweet potato using the greener analytical approach.

A precisely weighed $4.0 \mathrm{mg}$ of the contents from the soft gelatin capsules were dissolved in $10 \mathrm{~mL}$ of hexane: acetone (50:50 percent) for the measurement of $\beta$-carotene in commercial formulation A (soft gelatin capsules). Under lowered pressure, the solvent was 
evaporated. To reconstitute the remaining residue, $10 \mathrm{~mL}$ hexane: acetone (50:50 percent) was used. This solution was ultrasonicated at $50{ }^{\circ} \mathrm{C}$ for about one hour. This solution was utilized for the determination of $\beta$-carotene, utilizing the greener reversed-phase HPTLC approach.

\subsection{Validation Studies}

Following the ICH-Q2 (R1) criteria, the greener reversed-phase HPTLC approach for determining $\beta$-carotene was verified for varied validation settings [46]. By graphing $\beta$-carotene concentrations against its measured chromatographic response, the linearity of $\beta$-carotene was determined. For the greener reversed-phase HPTLC approach, the $\beta$ carotene linearity was tested in the $25-1000 \mathrm{ng}_{\text {band }}{ }^{-1}$ range. The "retardation factor $\left(\mathrm{R}_{\mathrm{f}}\right)$, asymmetry factor (As), and theoretical plates number $\left(\mathrm{N} \mathrm{m}^{-1}\right)^{\prime \prime}$ were used to evaluate the system appropriateness characteristics for the greener reversed-phase HPTLC approach. The " $\mathrm{R}_{\mathrm{f}}$, As, and $\mathrm{N} \mathrm{m}^{-1 \text { " }}$ values were computed using the equations previously given [47].

The percent recovery, which was evaluated at LQC (100 ng band $\left.{ }^{-1}\right), \mathrm{MQC}\left(400 \mathrm{ng} \mathrm{band}^{-1}\right)$, and HQC (1000 ng band $\left.^{-1}\right)$ for the greener reversed-phase HPTLC approach, was used to assess the accuracy of the greener reversed-phase HPTLC approach.

The intra/interday precision of the greener reversed-phase HPTLC approach was examined. Analysis of $\beta$-carotene at LQC, MQC, and HQC on the same day was used to determine intraday fluctuation. The study of $\beta$-carotene at LQC, MQC, and HQC on three different days was used to assess interday variation [46].

The robustness of the suggested analytical approach was tested by including some minor changes in the greener mobile phase. The original EtOH-CY-A $\left(95: 2.5: 2.5, v v v^{-1}\right)$ greener mobile phase was replaced with EtOH-CY-A (96:2:2 $\left.v v v^{-1}\right)$ and EtOH-CY-A $\left(94: 3: 3 v v v^{-1}\right)$ greener mobile phases, with the necessary chromatographic adjustments reported [46].

Using the standard deviation technique of blank, the sensitivity of the greener reversedphase HPTLC methodology was examined as "detection (LOD) and quantification (LOQ) limits". The "LOD and LOQ" for $\beta$-carotene were computed using conventional methods previously described $[46,47]$.

By comparing the $R_{f}$ values and superimposed UV absorption spectra of $\beta$-carotene in TE of different fractions of carrots and sweet potato, UBE of different fractions of carrots and sweet potato, and commercial formulation A with those of standard $\beta$-carotene, the peak purity/specificity for the greener reversed-phase HPTLC approach was assessed.

\subsection{Determination of $\beta$-Carotene in TE and UBE of Carrots, Sweet Potato, and Marketed Formulation $A$}

The chromatographic responses of the prepared TE and UBE solutions of carrots, sweet potato, and commercial formulation A were observed on reversed-phase silica gel TLC plates. The $\beta$-carotene content of all produced solutions was calculated using the $\beta$-carotene calibration curve for the greener reversed-phase HPTLC approach.

\subsection{Greenness Assessment}

The "AGREE metric technique" [44] was used to assess the greenness of the greener reversed-phase HPTLC technology. The "AGREE: The Analytical Greenness Calculator (version 0.5, Gdansk University of Technology, Gdansk, Poland, 2020)" was used to calculate the AGREE scale (0.0-1.0) of the greener reversed-phase HPTLC technique.

\section{Results and Discussion}

\subsection{Method Development}

In the literature, there is a scarcity of green analytical methodologies for determining $\beta$-carotene. As a result, the goal of this study was to develop and validate a rapid, sensitive, and environmentally friendly reversed-phase HPTLC approach for determining $\beta$-carotene in TE and UBE fractions of carrots, sweet potatoes, and commercial formulations. 
For the $\beta$-carotene estimation utilizing the greener reversed-phase HPTLC approach, different proportions of EtOH, CY, and A, including EtOH-CY-A (50:25:25, $\left.v v v^{-1}\right)$, EtOHCY-A (60:20:20, $\left.v v v^{-1}\right)$, EtOH-CY-A (70:15:15, $\left.v v v^{-1}\right)$, EtOH-CY-A (80:10:10, $\left.v v v^{-1}\right)$, EtOH-CY-A (85:7.5:7.5, $\left.v v v^{-1}\right)$, EtOH-CY-A (90:5:5, $\left.v v v^{-1}\right)$, and EtOH-CY-A (95:2.5:2.5, $v$ $v v^{-1}$ ) were evaluated as the greener solvent mixtures for the establishment of a reliable band for the determination of $\beta$-carotene in TE and UBE of different fractions of carrots, sweet potato, and marketed formulation. Figure 2 shows a representative image of the greener mobile phase, which was created under chamber saturation conditions.

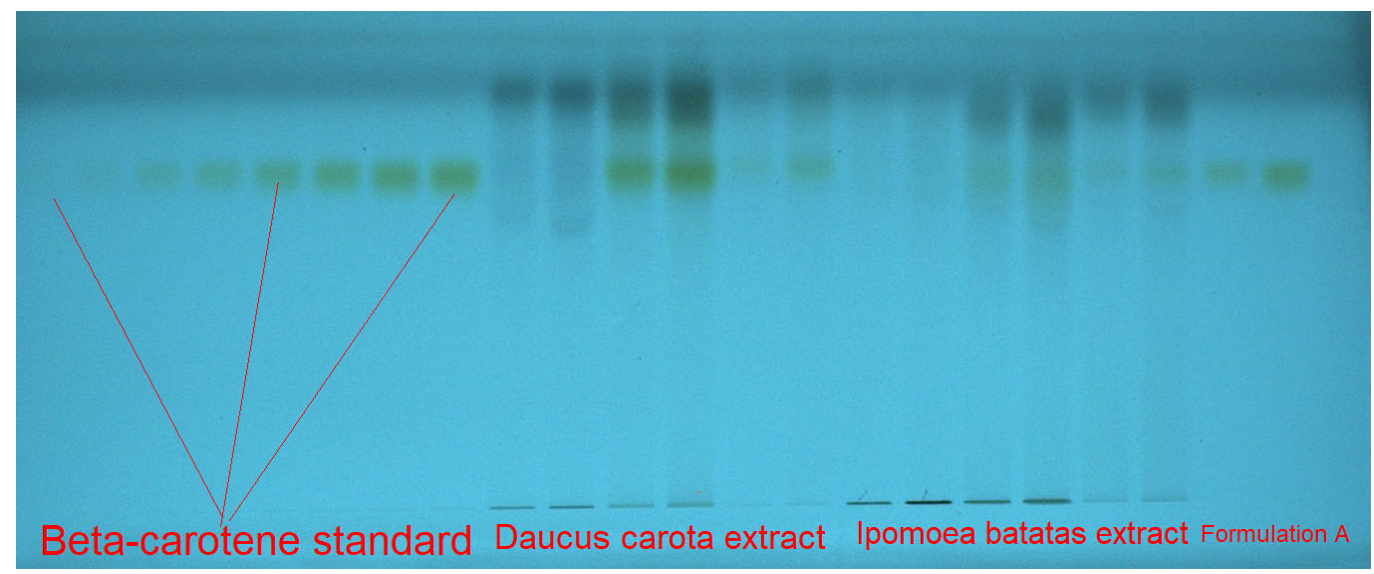

Figure 2. Developed thin-layer chromatography (TLC) plate for standard $\beta$-carotene, Daucus carota extract, Ipomea batatas extract, and commercial formulation A established using EtOH-CY-A (95:2.5:2.5, $\left.v v v^{-1}\right)$ as the greener mobile phase for the greener reversed-phase HPTLC approach.

The findings revealed that EtOH-CY-A (50:25:25, $\left.v v v^{-1}\right)$, EtOH-CY-A (60:20:20, $v v$ $\left.v^{-1}\right)$, EtOH-CY-A (70:15:15, $\left.v v v^{-1}\right)$, EtOH-CY-A (80:10:10, $\left.v v v^{-1}\right)$, EtOH-CY-A (85:7.5:7.5, $\left.v v v^{-1}\right)$, and EtOH-CY-A (90:5:5, $\left.v v v^{-1}\right)$ greener solvent mixtures presented a poor chromatogram of $\beta$-carotene with a high value of As (As = 1.15-1.27). However, the EtOH-CY-A (95:2.5:2.5, $\left.v v v^{-1}\right)$ greener mobile phase presented a well-resolved peak of $\beta$-carotene at $R_{f}=0.64 \pm 0.02$ with a reliable value of As (As $\left.=1.03\right)$ as indicated in Figure 3 .

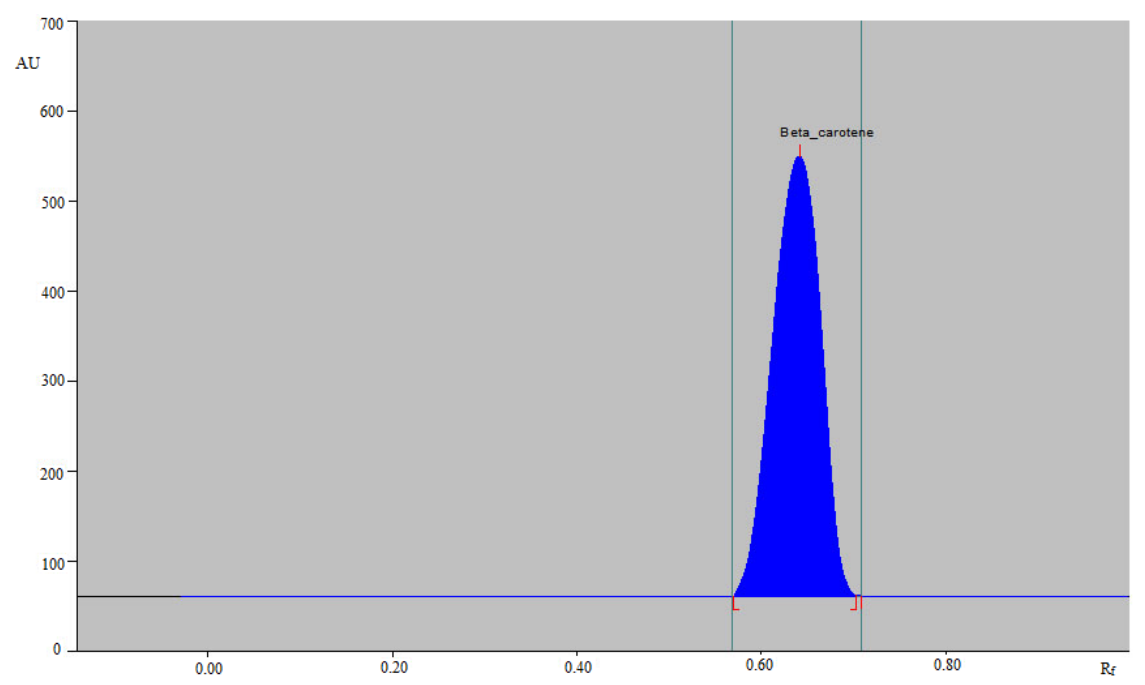

Figure 3. Representative chromatogram of pure $\beta$-carotene for the greener reversed-phase HPTLC approach.

As a result, for the determination of $\beta$-carotene in TE and UBE of various fractions of carrots, sweet potato, and commercial formulation, the EtOH-CY-A (90:2.5:2.5, $\left.v v v^{-1}\right)$ 
greener mobile phase was chosen as the final mobile phase system. The chromatogram for the greener reversed-phase HPTLC approach was densitometrically examined, and the greatest chromatographic response for the greener reversed-phase HPTLC approach was determined at $459 \mathrm{~nm}$. Hence, all the analyses of $\beta$-carotene were performed at $459 \mathrm{~nm}$.

\subsection{Validation Studies}

The greener reversed-phase HPTLC approach for the determination of $\beta$-carotene was validated for various parameters by following the ICH-Q2-R1 recommendations [46]. The results for the regression analysis for linearity of the calibration plot of $\beta$-carotene for the proposed analytical approach are shown in Table 1 . The $\beta$-carotene calibration curve was linear in the $25-1000 \mathrm{ng}^{\text {band }}{ }^{-1}$ range for the greener analytical approach. The values of "determination coefficient $\left(R^{2}\right)$ " and "regression coefficient $(R)$ " for $\beta$-carotene were predicted as 0.9985 and 0.9992 , respectively for the greener analytical approach. These observations offered good linearity between the $\beta$-carotene concentration and its chromatographic response.

Table 1. The regression analysis results for the determination of $\beta$-carotene utilizing a greener reversed-phase "high-performance thin-layer chromatography (HPTLC)" approach a .

\begin{tabular}{cc}
\hline Parameters & Values \\
\hline Linearity range $\left(\right.$ ng band $^{-1}$ ) & $25-1000$ \\
Regression equation & $\mathrm{y}=47.696 \mathrm{x}+297.73$ \\
$\mathrm{R}^{2}$ & 0.9985 \\
$\mathrm{R}$ & 0.9992 \\
Slope $\pm \mathrm{SD}$ & $47.696 \pm 1.9400$ \\
Intercept \pm SD & $297.73 \pm 3.4100$ \\
Standard error of slope & 0.79216 \\
Standard error of intercept & 1.3924 \\
95\% confidence interval of slope & $44.287-51.104$ \\
$95 \%$ confidence interval of intercept & $291.73-303.72$ \\
LOD \pm SD $($ ng band \\
LOQ \pm SD (ng band $^{-1}$ ) & $8.84 \pm 0.12$ \\
\hline
\end{tabular}

a Mean \pm SD; $n=6$; LOD: limit of detection; LOQ: limit of quantification.

Table 2 shows the results of the system suitability parameters for the greener reversedphase HPTLC approach. For the greener analytical approach, the " $\mathrm{R}_{\mathrm{f}}, \mathrm{As}$, and $\mathrm{N} \mathrm{m}^{-1}$ " were calculated as $0.64 \pm 0.02,1.03 \pm 0.03$, and $5741 \pm 3.52$, respectively. These findings demonstrated that the greener analytical approach was reliable in determining $\beta$-carotene in TE and UBE of various carrot fractions, sweet potato fractions, and marketed formulations.

Table 2. System suitability factors, such as retardation factor $\left(R_{\mathrm{f}}\right)$, asymmetry factor (As), and theoretical plates number $\left(\mathrm{N} \mathrm{m}^{-1}\right)$ of $\beta$-carotene for a greener reversed-phase HPTLC approach ${ }^{\text {a }}$.

\begin{tabular}{cc}
\hline Parameters & Value \\
\hline $\mathrm{R}_{\mathrm{f}}$ & $0.64 \pm 0.02$ \\
$\mathrm{As}$ & $1.03 \pm 0.03$ \\
$\mathrm{~N} \mathrm{~m}^{-1}$ & $5741 \pm 3.52$ \\
\hline
\end{tabular}

$\bar{a}$ Mean $\pm \mathrm{SD} ; n=3$.

Table 3 contains the results of the accuracy estimation for the greener analytical approach. At LQC, MQC, and HQC, the percent recovery of $\beta$-carotene was calculated to be 101.23 percent, 99.41 percent, and 101.22 percent, respectively, for the greener analytical approach. The accuracy of the greener analytical approach for the determination of $\beta$ carotene in TE and UBE of different fractions of carrots, sweet potato, and marketed formulation was represented by these percent accuracy values. 
Table 3. Evaluation of accuracy of $\beta$-carotene for a greener reversed-phase HPTLC approach ${ }^{\text {a }}$.

\begin{tabular}{cccc}
\hline Conc. (ng Band-1) & Conc. Found (ng Band-1) \pm SD & Recovery (\%) & CV (\%) \\
\hline 100 & $101.23 \pm 0.61$ & 101.23 & 0.60 \\
400 & $397.64 \pm 2.17$ & 99.41 & 0.54 \\
1000 & $1010.24 \pm 4.64$ & 101.02 & 0.45 \\
\hline
\end{tabular}

a Mean \pm SD; $n=6$.

The precision evaluation results for the greener analytical approach were predicted in terms of percent of the coefficient of variation (percent CV), as shown in Table 4. Using the intraday precision, the percent $\mathrm{CVs}$ of $\beta$-carotene for the greener analytical approach were assessed to be 0.50 percent, 0.47 percent, and 0.46 percent at LQC, MQC, and HQC, respectively. For the intermediate precision, the percent $\mathrm{CVs}$ of $\beta$-carotene for the greener analytical approach were 0.64 percent, 0.55 percent, and 0.47 percent at LQC, MQC, and $\mathrm{HQC}$, respectively. These values of percent CV showed the precision of the greener analytical approach for the determination of $\beta$-carotene in TE and UBE of different fractions of carrots, sweet potato, and commercial formulation.

Table 4. Measurement of intra/inter-day precision of $\beta$-carotene for a greener reversed-phase HPTLC approach $^{\mathrm{a}}$.

\begin{tabular}{ccccccc}
\hline \multirow{2}{*}{$\begin{array}{c}\text { Conc. } \\
\text { (ng Band }^{-1} \text { ) }\end{array}$} & \multicolumn{2}{c}{ Intraday Precision } & \multicolumn{3}{c}{ Interday Precision } \\
\cline { 2 - 7 } & $\begin{array}{c}\text { Conc. (ng Band } \\
\text { 土 SD }\end{array}$ & Standard Error & CV (\%) & $\begin{array}{c}\text { Conc. (ng Band } \\
\pm \text { SD }\end{array}$ & Standard Error & CV (\%) \\
\hline 100 & $98.36 \pm 0.50$ & 0.20 & 0.50 & $98.74 \pm 0.64$ & 0.26 & 0.64 \\
400 & $406.31 \pm 1.94$ & 0.79 & 0.47 & $396.21 \pm 2.19$ & 0.89 & 0.55 \\
1000 & $988.23 \pm 4.58$ & 1.87 & 0.46 & $1008.54 \pm 4.78$ & 1.95 & 0.47 \\
\hline
\end{tabular}

${ }^{\mathrm{a}}$ Mean $\pm \mathrm{SD} ; n=6$.

Table 5 summarizes the findings of the robustness investigation for the greener reversed-phase analytical approach. For the greener analytical approach, the percent $\mathrm{CVs}$ for the robustness analysis were assessed to be $0.74-0.84$ percent. For the greener analytical approach, the $R_{f}$ values of $\beta$-carotene were anticipated to be $0.63-0.65$. The durability of the greener analytical approach for the detection of $\beta$-carotene in TE and UBE of different fractions of carrots, sweet potato, and commercial formulation was demonstrated by modest fluctuations in $R_{f}$ values of $\beta$-carotene and low percent CVs.

Table 5. Robustness analysis for $\beta$-carotene for a greener reversed-phase HPTLC approach ${ }^{\text {a }}$

\begin{tabular}{|c|c|c|c|c|c|c|}
\hline \multirow{2}{*}{$\begin{array}{c}\text { Conc. } \\
\left(\text { ng Band }{ }^{-1}\right)\end{array}$} & \multicolumn{3}{|c|}{ Mobile Phase Composition (EtOH-CY-A, $v v v^{-1}$ ) } & \multicolumn{3}{|c|}{ Results } \\
\hline & Original & Used & Level & Conc. (ng Band $\left.{ }^{-1}\right) \pm$ SD & $\% \mathrm{CV}$ & $\mathbf{R}_{\mathrm{f}}$ \\
\hline \multirow{3}{*}{400} & \multirow{3}{*}{$95: 2.5: 2.5$} & $96: 2: 2$ & +1.0 & $387.42 \pm 2.87$ & 0.74 & 0.63 \\
\hline & & $95: 2.5: 2.5$ & 0.0 & $398.21 \pm 3.14$ & 0.78 & 0.64 \\
\hline & & $94: 3: 3$ & -1.0 & $406.21 \pm 3.45$ & 0.84 & 0.65 \\
\hline
\end{tabular}

${ }^{\mathrm{a}}$ Mean $\pm \mathrm{SD} ; n=6$.

The "LOD and LOQ" values for the greener analytical approach were obtained, and these results are given in Table 1. The "LOD and LOQ" for the greener analytical approach were computed as $8.84 \pm 0.12$ and $26.52 \pm 0.36 \mathrm{ng}^{\text {band }}{ }^{-1}$, respectively for the determination of $\beta$-carotene. The sensitivity of the greener analytical approach for the determination of $\beta$-carotene in TE and UBE of different fractions of carrots, sweet potato, and commercial formulation was demonstrated by these "LOD and LOQ" values for the greener analytical approach.

By comparing the superimposed UV spectra of $\beta$-carotene in different fractions of carrots, sweet potato, and commercial formulation with those of standard $\beta$-carotene, the peak purity/specificity for the greener analytical approach was evaluated. Figure 4 depicts 
the superimposed UV spectra of standard $\beta$-carotene and $\beta$-carotene in various fractions of carrots, sweet potato, and commercial formulation. For the greener analytical approach, the maximum densitometric response for $\beta$-carotene in standard $\beta$-carotene and $\beta$-carotene in varied fractions of carrots, sweet potato, and commercial formulation was determined at $459 \mathrm{~nm}$. The peak purity/specificity for the greener analytical approach was demonstrated by the same UV spectra, $R_{\mathrm{f}}$ values, and wavelength of $\beta$-carotene in standard $\beta$-carotene and $\beta$-carotene in varied fractions of carrots, sweet potato, and commercial formulation.

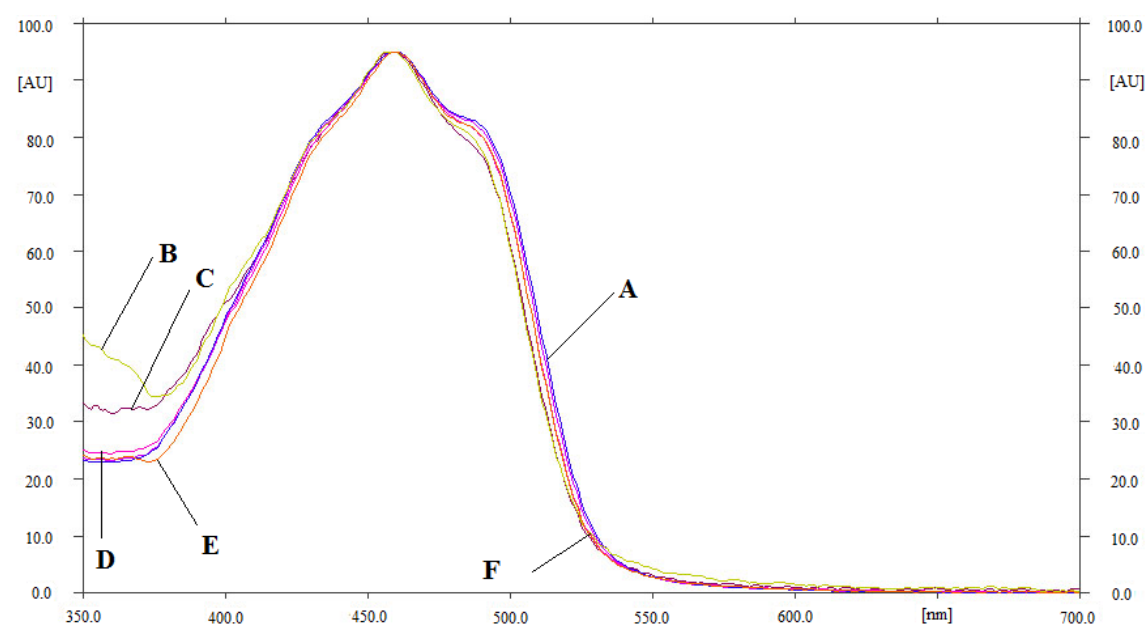

Figure 4. Superimposed UV absorption spectra of (A) pure $\beta$-carotene, (B) D. carota (hexane: acetone 50:50\%), (C) D. carota (acetone 100\%), (D) commercial formulation A, (E) I. batatas (hexane: acetone $50: 50 \%$ ), and (F) I. batatas (acetone $100 \%$ ).

\subsection{Determination of $\beta$-Carotene in TE and UBE of Carrots, Sweet Potato, and Marketed Formulation A}

The greener reversed-phase HPTLC approach was applied in the determination of $\beta$-carotene in TE and UBE of varied fractions of carrots, sweet potato, and marketed formulation $\mathrm{A}$. The chromatographic peaks of $\beta$-carotene from TE and UBE of varied fractions of carrots, sweet potato, and marketed formulation were verified by comparing their single TLC spot at $R_{f}=0.64 \pm 0.02$ with those of a standard $\beta$-carotene for the greener analytical approach. The chromatographic peaks of $\beta$-carotene in all studied sample matrices were recorded at $R_{\mathrm{f}}=0.64 \pm 0.02$ without the presence of additional peaks.

The content $\left(\% w w^{-1}\right)$ of $\beta$-carotene in all investigated sample matrices were determined by the calibration curve of $\beta$-carotene and results are summarized in Table 6 . The content of $\beta$-carotene in TE and UBE of carrots (hexane $100 \%$ ) was not detected. The content of $\beta$-carotene in TE of carrots (acetone 100\%), carrots (hexane: acetone 50:50\%), sweet potato (hexane 100\%), sweet potato (acetone 100\%), sweet potato (hexane: acetone 50:50\%), and commercial formulation A was computed as $3.22 \pm 0.08,10.32 \pm 0.14,0.85 \pm 0.02$, $2.29 \pm 0.04 \%, 3.73 \pm 0.09 \%$, and $6.73 \pm 0.134 \% w w^{-1}$, respectively. However, the content of $\beta$-carotene in UBE of carrots (acetone 100\%), carrots (hexane: acetone 50:50\%), sweet potato (hexane 100\%), sweet potato (acetone 100\%), sweet potato (hexane: acetone 50:50\%), and commercial formulation A was computed as $4.31 \pm 0.11,12.35 \pm 0.20,1.06 \pm 0.03$, $3.11 \pm 0.05 \%, 4.86 \pm 0.10 \%$, and $8.52 \pm 0.16 \% w w^{-1}$, respectively. The amount of $\beta$ carotene in ethanolic extracts of carrots has been reported as $30.30 \mu \mathrm{g} \mathrm{L}^{-1}$, using the UV spectrometry approach [18]. The amount of $\beta$-carotene in acetone and oleyl alcohol fractions of carrots has been reported as $112.10 \mu^{-1} \mathrm{~g}^{-1}$ [24] and $41.06 \mu \mathrm{g} \mathrm{g}^{-1}$ [28], respectively using the HPLC approach. The amount of similar carotenoids, such as lycopene in various red-fleshed watermelon cultivars has been reported in the range of $3.91-6.30 \% w w^{-1}$ using a spectrometry approach [48]. The amount of $\beta$-carotene recorded in different fractions of carrots and sweet potato in this study were considerably higher than those reported by UV and HPLC methods in literature $[18,24,28]$. However, the amount of $\beta$-carotene 
recorded in different fractions of carrots and sweet potato in this study were comparable to those reported for lycopene using the spectrometry approach [48]. As a result, the studied fractions and proposed analytical methodology could be considered superior over reported UV and HPLC methods for the determination of $\beta$-carotene, and similar to the reported spectrometry approach for lycopene determination. The content of $\beta$-carotene was computed to be higher in TE and UBE of carrots (hexane: acetone 50:50\%) fraction compared to other fractions of carrots and sweet potato studied. In addition, the content of $\beta$-carotene was significantly higher in UBE of all sample matrices in comparison to respective TE $(p<0.05)$. The UBE approach for extracting $\beta$-carotene in different fractions of carrots, sweet potato, and marketed formulation A is superior to the TE method of extraction based on these observations and results.

Table 6. Application of a greener reversed-phase HPTLC approach for the determination of $\beta$-carotene in TE and UBE of different fractions of D. carota and I. batatas and commercial formulation A ${ }^{\text {a }}$.

\begin{tabular}{ccc}
\hline Samples & TE & UBE \\
\hline \multicolumn{3}{c}{ Amount of $\boldsymbol{\beta}$-Carotene $\mathbf{( \% ~ w ~ w ~ w ~} \mathbf{~}^{\mathbf{1}}$ ) } \\
\hline D. carota (Hexane 100\%) & $0.00 \pm 0.00$ & $0.00 \pm 0.00$ \\
D. carota (Acetone 100\%) & $3.22 \pm 0.08$ & $4.31 \pm 0.11$ \\
D. carota (Hexane: acetone 50:50\%) & $10.32 \pm 0.14$ & $12.35 \pm 0.20$ \\
I. batatas (Hexane 100\%) & $0.85 \pm 0.02$ & $1.06 \pm 0.03$ \\
I. batatas (Acetone 100\%) & $2.29 \pm 0.04$ & $3.11 \pm 0.05$ \\
I. batatas (Hexane: acetone 50:50\%) & $3.73 \pm 0.09$ & $4.86 \pm 0.10$ \\
Formulation A & $6.73 \pm 0.13$ & $8.52 \pm 0.16$ \\
\hline a Mean \pm SD; $n=3$. &
\end{tabular}

Overall, these findings and results showed that the greener analytical approach can be successfully used to determine $\beta$-carotene in a variety of food and pharmaceutical samples containing $\beta$-carotene as an active medicinal ingredient.

\subsection{Greenness Evaluation}

For evaluating the greenness of analytical procedures, various qualitative and quantitative methodologies have been presented [40-45]. Only the AGREE quantitative technique, on the other hand, assesses GAC using all twelve components/principles [44]. As a result, the proposed analytical approach's greenness features were computed utilizing "AGREE: The Analytical Greenness Calculator (version 0.5, Gdansk University of Technology, Gdansk, Poland, 2020)". Figure 5 shows the computed AGREE scale for the greener analytical approach with respect to the twelve GAC principles. Figure 6 depicts the AGREE report sheet and AGREE scale for each particular GAC principle. The overall AGREE scale for the greener analytical technique was 0.81 , indicating that the greener profile for determining $\beta$-carotene is excellent.

\subsection{Comparison with Literature Analytical Approaches}

For the determination of $\beta$-carotene, the greener reversed-phase HPTLC approach was compared to literature analytical approaches. The comparison results are summarized in Table 7. Three primary validation criteria of the greener reversed-phase HPTLC approach were compared to existing analytical approaches, including "linearity range, accuracy, and precision. A reported HPLC approach's linearity range and accuracy were $0.20-35 \mu^{-1} g^{-1}$ and $97.94-101.02 \%$, respectively, which were somewhat less than the greener reversed-phase HPTLC approach (linearity range $=25-1000 \mathrm{ng}_{\text {band }}{ }^{-1}$ and accuracy $=99.41-101.23 \%$ ) [18]. Another HPLC approach's linearity range, accuracy, and precision were reported as $0.10-50 \mu \mathrm{g} \mathrm{mL}^{-1}, 97.50-102.10 \%$, and $1.20-4.40 \%$ respectively, all of which were inferior to the greener reversed-phase HPTLC approach [23]. The reported HPTLC approach has a linearity range of $0.76-9.14 \mu \mathrm{g} \mathrm{band}^{-1}$, which was significantly inferior than the greener reversed-phase HPTLC approach [31]. 


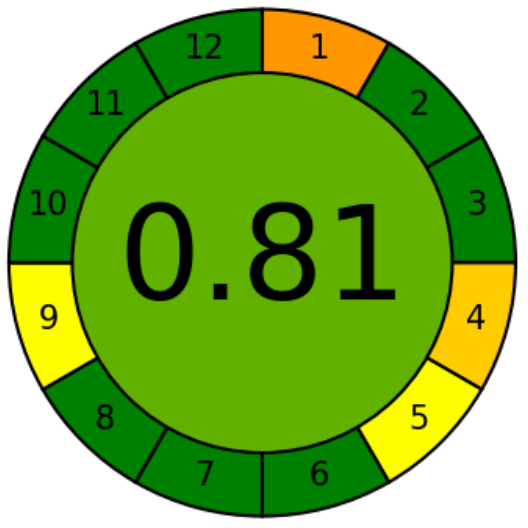

1. Sample treatment

2. Sample amount

3. Device positioning

4. Sample prep. stages

5. Automation, miniaturization

6. Derivatization

7. Waste

8. Analysis throughput

9. Energy consumption

10 . Source of reagents

11. Toxicity

12. Operator's safety

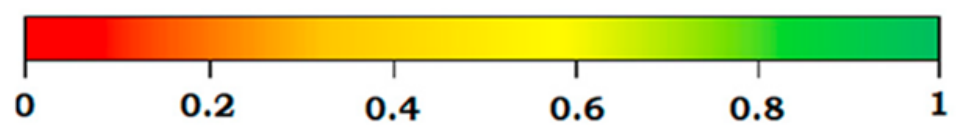

Figure 5. "Analytical GREEnness (AGREE)" scale for a greener reversed-phase HPTLC approach.

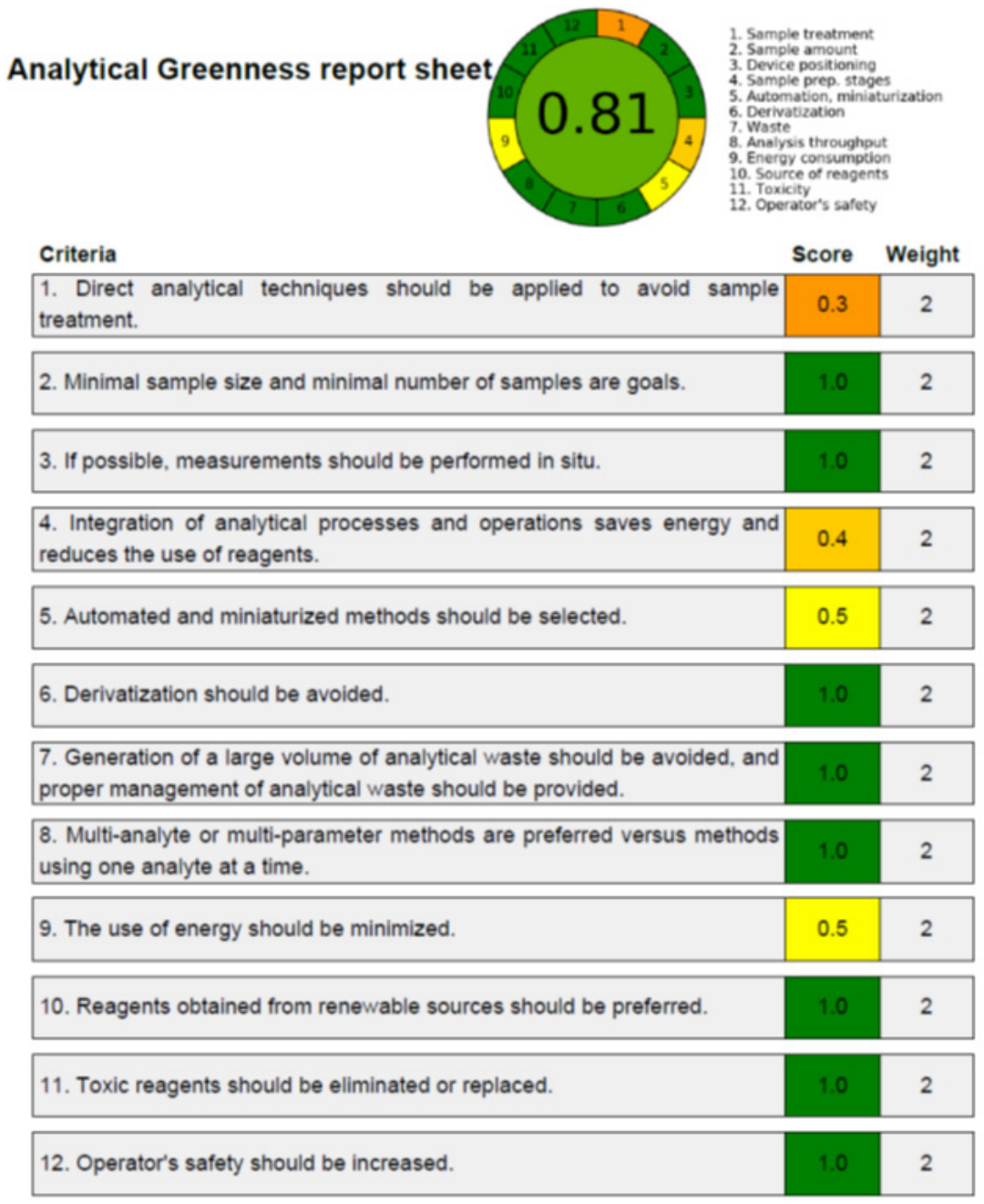

Figure 6. AGREE scale sheet for a greener reversed-phase HPTLC approach of $\beta$-carotene, demonstrating the AGREE scale for 12 different components/principles of GAC. 
Table 7. Comparative evaluation of the greener HPTLC approach with reported analytical approaches for the determination of $\beta$-carotene.

\begin{tabular}{ccccc}
\hline $\begin{array}{c}\text { Analytical } \\
\text { Method }\end{array}$ & Linearity Range & $\begin{array}{c}\text { Accuracy (\% } \\
\text { Recovery) }\end{array}$ & Precision (\% CV) & Ref. \\
\hline HPLC & $0.20-35\left(\mu \mathrm{g} \mathrm{g}^{-1}\right)$ & $97.94-101.02$ & - & {$[18]$} \\
HPLC & $0.10-50\left(\mu \mathrm{g} \mathrm{mL}^{-1}\right)$ & $97.50-102.10$ & $1.20-4.40$ & {$[23]$} \\
HPTLC & $0.76-9.14\left(\mu \mathrm{g} \mathrm{band}^{-1}\right)$ & $99.59-101.04$ & $0.68-0.87$ & {$[31]$} \\
HPTLC & $25-1000\left(\mathrm{ng} \mathrm{band}^{-1}\right)$ & $99.41-101.23$ & $0.46-0.64$ & Present work \\
\hline
\end{tabular}

However, the described HPTLC approach's accuracy and precision were comparable to the greener reversed-phase HPTLC approach [31]. All of these findings pointed to the superiority of the greener reversed-phase HPTLC approach for determining $\beta$-carotene over previously reported HPLC and HPTLC approaches in addition to the greener nature of the proposed analytical approach.

\section{Conclusions}

Due to the lack of a greener HPTLC approach for determining $\beta$-carotene in the literature, this study was conducted to develop and validate a rapid, sensitive, and greener reversed-phase HPTLC approach for determining $\beta$-carotene in TE and UBE of different fractions of carrots, sweet potato, and marketed formulation. For the determination of $\beta$-carotene, the greener analytical approach is sensitive, rapid, accurate, precise, robust, and greener. When compared to its TE, the UBE of carrots, sweet potato, and marketed formulation A had considerably more $\beta$-carotene. As a result, the UBE approach is suggested as the preferred method for extracting $\beta$-carotene from various fractions of carrots, sweet potato, and marketed formulations. The computed overall AGREE scale for the greener analytical approach suggested the excellent greener nature of the method for $\beta$ carotene estimation. The amount of $\beta$-carotene recorded in different fractions of carrots and sweet potato in this study were considerably higher than those reported by UV and HPLC methods in literature. Hence, the studied fractions and proposed analytical methodology could be considered superior over reported UV and HPLC methods for the determination of $\beta$-carotene. These findings suggest that the greener reversed-phase HPTLC approach can be used to determine $\beta$-carotene in a variety of food and pharmaceutical samples containing $\beta$-carotene as an active medicinal ingredient.

Author Contributions: Conceptualization, P.A. and F.S.; methodology, P.A., A.A. (Aftab Alam), M.H.A. and A.I.F.; software, M.M.G.; validation, S.A., A.A., and S.A.; formal analysis, A.A. (Abuzer Ali); investigation, P.A. and A.A. (Aftab Alam); resources, A.A. (Abuzer Ali); data curation, M.M.G.; writing-original draft preparation, F.S.; writing-review and editing, S.A., P.A. and M.H.A.; visualization, A.A. (Abuzer Ali); supervision, F.S. and M.H.A.; project administration, F.S.; funding acquisition, A.A. (Abuzer Ali). All authors have read and agreed to the published version of the manuscript.

Funding: This research was funded by the Taif University Researchers Supporting Project (Number TURSP-2020/124), Taif University, Taif, Saudi Arabia and APC was funded by TURSP.

Institutional Review Board Statement: Not applicable.

Informed Consent Statement: Not applicable.

Data Availability Statement: This study did not report any data.

Acknowledgments: Authors are thankful to the Taif University Researchers Supporting Project (Number TURSP-2020/124), Taif University, Taif, Saudi Arabia for supporting this work.

Conflicts of Interest: The authors declare no conflict of interest. 


\section{References}

1. Haskell, M.J. The challenge to reach nutritional adequacy for vitamin A: $\beta$-carotene bioavailability and conversion-Evidence in humans. Am. J. Clin. Nutr. 2012, 96, 1193S-1203S. [CrossRef] [PubMed]

2. Sommer, A.; Vyas, K.S. A global clinical view on vitamin A and carotenoids. Am. J. Clin. Nutr. 2012, 96, 1204S-1206S. [CrossRef]

3. Kim, J.K. An update on the potential health benefits of carotenes. EXCLI J. 2016, 15, 1-4. [CrossRef] [PubMed]

4. Prieto, J.M.; Chandrasekara, A.; Josheph, K.T. Roots and tuber crops as functional foods: A review on phytochemical constituents and their potential health benefits. Int. J. Food Sci. 2016, 2016, E3631647.

5. Blando, F.; Marchello, S.; Maiorano, G.; Durante, M.; Signore, A.; Laus, M.; Soccio, M.; Mita, G. Bioactive Compounds and Antioxidant Capacity in Anthocyanin-Rich Carrots: A Comparison between the Black Carrot and the Apulian Landrace "Polignano" Carrot. Plants 2021, 10, 564. [CrossRef]

6. Arscott, S.A.; Tanumihardjo, S.A. Carrots of Many Colors Provide Basic Nutrition and Bioavailable Phytochemicals Acting as a Functional Food. Compr. Rev. Food Sci. Food Saf. 2010, 9, 223-239. [CrossRef]

7. Andersen, O.M.; Jordheim, M. Basic anthocyanin chemistry and dietary Sources. In Anthocyanins in Health and Disease; Wallace, T.C., Giusti, M.M., Eds.; Taylor \& Francis Inc.: Abingdon, UK; CRC Press: New York, NY, USA, 2013; pp. 13-90.

8. Blando, F.; Calabriso, N.; Berland, H.; Maiorano, G.; Gerardi, C.; Carluccio, M.A.; Andersen, Ø.M. Radical scavenging and biological activities of representative anthocyanin groupings from pigment-rich fruits and vegetables. Int. J. Mol. Sci. 2018, 19, 169. [CrossRef]

9. Esatbeyoglu, T.; Rodríguez-Werner, M.; Schlösser, A.; Liehr, M.; Ipharraguerre, I.; Winterhalter, P.; Rimbach, G. Fractionation of Plant Bioactives from Black Carrots (Daucus carota subspecies sativus varietas atrorubens Alef.) by Adsorptive Membrane Chromatography and Analysis of Their Potential Anti-Diabetic Activity. J. Agric. Food Chem. 2016, 64, 5901-5908. [CrossRef]

10. Bendokas, V.; Stanys, V.; Mažeikienè, I.; Trumbeckaite, S.; Baniene, R.; Liobikas, J. Anthocyanins: From the Field to the Antioxidants in the Body. Antioxidants 2020, 9, 819. [CrossRef]

11. Groppo, F.C.; Pochapski, M.T.; Fosquiera, E.C.; Esmerino, L.A.; Dos Santos, E.B.; Farago, P.V.; Santos, F.A. Phytochemical screening, antioxidant, and antimicrobial activities of the crude leaves' extract from Ipomoea batatas (L.) Lam. Pharmacogn. Mag. 2011, 7, 165-170. [CrossRef]

12. Dini, I.; Tenore, G.C.; Dini, A. Saponins in Ipomoea batatas tubers: Isolation, characterization, quantification and antioxidant properties. Food Chem. 2009, 113, 411-419. [CrossRef]

13. Khan, M.Z.; Takemura, M.; Maoka, T.; Otani, M.; Misawa, N. Carotenoid analysis of sweetpotato Ipomoea batatas and functional identification of its lycopene $\beta$ - and $\varepsilon$-cyclase genes. Zeitschrift für Naturforschung C 2016, 71, 313-322. [CrossRef] [PubMed]

14. Zheng, W.; Clifford, M.N. Profiling the chlorogenic acids of sweet potato (Ipomoea batatas) from China. Food Chem. 2008, 106, 147-152. [CrossRef]

15. Rumbaoa, R.G.O.; Cornago, D.F.; Geronimo, I.M. Phenolic content and antioxidant capacity of Philippine sweet potato (Ipomoea batatas) varieties. Food Chem. 2009, 113, 1133-1138. [CrossRef]

16. Miyazaki, Y.; Kusano, S.; Doi, H.; Aki, O. Effects on immune response of antidiabetic ingredients from white-skinned sweet potato (Ipomoea batatas L.). Nutrition 2005, 21, 358-362. [CrossRef] [PubMed]

17. Kwon, H.C.; Jung, C.M.; Shin, C.G.; Lee, J.K.; Choi, S.U.; Kim, S.Y.; Lee, K.R. A New Caffeoyl Quinic Acid from Aster scaber and Its Inhibitory Activity against Human Immunodeficiency Virus-1(HIV-1) Integrase. Chem. Pharm. Bull. 2000, 48, 1796-1798. [CrossRef]

18. Mustapha, Y.; Babura, S.R. Determination of carbohydrate and $\beta$-carotene content of some vegetables consumed in Kana metropolis, Nigeria. Bay. J. Pure Appl. Sci. 2009, 2, 119-121.

19. Nagata, M. A simple spectrophotometric method for the estimation of beta-carotene content in spinach acetone extracts. Bull. Natl. Inst. Veg. Tea Sci. 2009, 8, 1-5.

20. Speek, A.; Temalilwa, C.; Schrijver, J. Determination of $\beta$-carotene content and vitamin A activity of vegetables by highperformance liquid chromatography and spectrophotometry. Food Chem. 1986, 19, 65-74. [CrossRef]

21. Takahata, Y.; Noda, T.; Nagata, T. HPLC determination of $\beta$-carotene content of sweet potato cultivars and its relationship with color values. Jpn. J. Breed. 1993, 43, 421-427. [CrossRef]

22. Schuep, W.; Schierle, J. Determination of $\beta$-Carotene in Commercial Foods: Interlaboratory Study. J. AOAC Int. 1997, 80, 1057-1064. [CrossRef]

23. Szpylka, J.; DeVries, J.W.; Bhandari, S.; Bui, M.H.; Ji, D.; Konings, E.; Lewis, R.; Mass, P.; Parish, H.; Post, B.; et al. Determination of $\beta$-carotene in supplements and raw materials by reversed-phase high pressure liquid chromatography. J. AOAC Int. 2005, 88, 1279-1291. [CrossRef] [PubMed]

24. Ahamad, M.N.; Saleemullah, M.; Shah, H.U.; Khalil, I.A.; Saljoqi, A.U.R. Determination of beta carotene content in fresh vegetables using high performance liquid chromatography. Sarhad J. Agric. 2007, 23, 767-770.

25. Gupta, P.; Sreelakshmi, Y.; Sharma, R. A rapid and sensitive method for determination of carotenoids in plant tissues by high performance liquid chromatography. Plant Methods 2015, 11, 5. [CrossRef] [PubMed]

26. Varzakas, T.; Kiokias, S. HPLC Analysis and Determination of Carotenoid Pigments in Commercially Available Plant Extracts. Curr. Res. Nutr. Food Sci. J. 2015, 4, 1-14. [CrossRef]

27. Dhankhar, J.; Sharma, R.; Mann, B. Optimization of various steps for RP-HPLC determination of $\beta$-carotene in milk fat. Int. Food Res. J. 2017, 24, 1393-1398. 
28. Dai, Y.; Row, K.H. Isolation and Determination of Beta-Carotene in Carrots by Magnetic Chitosan Beta-Cyclodextrin Extraction and High-Performance Liquid Chromatography (HPLC). Anal. Lett. 2019, 52, 1828-1843. [CrossRef]

29. Shi, L.; Zhu, X.L.; Liu, B.Z.; Gao, Y. Determination of beta-carotene in tobacco by HPTLC. Chin. J. Chromatogr. 1999, 17, 606-607.

30. Marsit, C.J.; Fried, B.; Sherma, J. High-performance thin-layer chromatographic analysis of lutein and beta-carotene in Cerithidia californica (Gastropoda) infected with two species of larval trematodes. J. Parasitol. 2000, 86, 635-636. [CrossRef]

31. Starek, M.; Guja, A.; Dabrowska, M.; Krzek, J. Assay of $\beta$-Carotene in Dietary Supplements and Fruit Juices by TLC-Densitometry. Food Anal. Methods 2015, 8, 1347-1355. [CrossRef]

32. Das, S.; Gupta, P.; De, B. Thin Layer Chromatographic Characterization of Carotenoid Isolates in Sugar Date Palm (Phoenix sylvestris) Fruit Epicarp and Inflorescence Axis. Int. J. Pharmacogn. Phytochem. Res. 2017, 9, 680-684. [CrossRef]

33. Hynstova, V.; Štěrbová, D.; Klejdus, B.; Hedbavny, J.; Huska, D.; Adam, V. Separation, identification and quantification of carotenoids and chlorophylls in dietary supplements containing Chlorella vulgaris and Spirulina platensis using High Performance Thin Layer Chromatography. J. Pharm. Biomed. Anal. 2018, 148, 108-118. [CrossRef]

34. Ghosh, S.; Chatterjee, J.K.; Chalkroborty, B.; Kundu, P. Estimation of beta carotene from fruit peel waste by high performance thin layer chromatography. J. Pharmacog. Phytochem. 2019, 8, 2598-2600.

35. Condurso, C.; Cincotta, F.; Tripodi, G.; Merlino, M.; Giarratana, F.; Verzera, A. A new approach for the shelf-life definition of minimally processed carrots. Postharvest Biol. Technol. 2020, 163, 111138. [CrossRef]

36. Cioates, C.N.; van Staden, J.F. Fluorimetric determination of $\beta$-carotene in food samples using a fluorescent dye. Anal. Lett. 2020, 53, 152-163. [CrossRef]

37. Baranska, M.; Schütze, A.W.; Schulz, H. Determination of Lycopene and $\beta$-Carotene Content in Tomato Fruits and Related Products: Comparison of FT-Raman, ATR-IR, and NIR Spectroscopy. Anal. Chem. 2006, 78, 8456-8461. [CrossRef]

38. Alam, P.; Ezzeldin, E.; Iqbal, M.; Anwer, K.; Mostafa, G.A.E.; Alqarni, M.H.; Foudah, A.I.; Shakeel, F. Ecofriendly densitometric RP-HPTLC method for determination of rivaroxaban in nanoparticle formulations using green solvents. RSC Adv. 2020, 10, 2133-2140. [CrossRef]

39. Alam, P.; Iqbal, M.; Ezzeldin, E.; Khalil, N.Y.; Foudah, A.I.; Alqarni, M.H.; Shakeel, F. Simple and accurate HPTLC-densitometry method for quantification of delafloxacin (a novel fluoroquinolone antibiotic) in plasma samples: Application to pharmacokinetic study in rats. Antibiotics 2020, 9, 134. [CrossRef]

40. Ibrahim, F.A.; Elmansi, H.; Fathy, M.E. Green RP-HPLC method for simultaneous determination of moxifloxacin combinations: Investigation of the greenness for the proposed method. Microchem. J. 2019, 148, 151-161. [CrossRef]

41. Abou-Taleb, N.H.; El-Enany, N.M.; El-Sherbiny, D.T.; El-Subbagh, H.I. Digitally enhanced thin layer chromatography for simultaneous determination of norfloxacin and tinidazole with the aid of Taguchi orthogonal array and desirability function approach: Greenness assessment by analytical Eco-Scale. J. Sep. Sci. 2019, 43, 1195-1202. [CrossRef]

42. Abdelrahman, M.M.; Abdelwahab, N.S.; Hegazy, M.A.; Fares, M.Y.; El-Sayed, G.M. Determination of the abused intravenously self-administered madness drops (Tropicamide) by liquid chromatography in rat plasma; an application to pharmacokinetic study and greenness profile assessment. Microchem. J. 2020, 159, 105582. [CrossRef]

43. Duan, X.; Liu, X.; Dong, Y.; Yang, J.; Zhang, J.; He, S.; Yang, F.; Wang, Z.; Dong, Y. A Green HPLC Method for Determination of Nine Sulfonamides in Milk and Beef, and Its Greenness Assessment with Analytical Eco-Scale and Greenness Profile. J. AOAC Int. 2020, 103, 1181-1189. [CrossRef]

44. Pena-Pereira, F.; Wojnowski, W.; Tobiszewski, M. AGREE-Analytical GREEnness Metric Approach and Software. Anal. Chem. 2020, 92, 10076-10082. [CrossRef] [PubMed]

45. Nowak, P.M.; Koscielniak, P. What Color Is Your Method? Adaptation of the RGB Additive Color Model to Analytical Method Evaluation. Anal. Chem. 2019, 91, 10343-10352. [CrossRef] [PubMed]

46. Guideline, I.H.T. Validation of analytical procedures: Text and methodology. Q2(R1) 2005, 1, 5.

47. Foudah, A.I.; Shakeel, F.; Alqarni, M.H.; Alam, P. A rapid and sensitive stability-indicating green RP-HPTLC method for the quantitation of flibanserin compared to green NP-HPTLC method: Validation studies and greenness assessment. Microchem. J. 2021, 164, 105960. [CrossRef]

48. Fish, W.W.; Perkins-Veazie, P.; Collins, J.K. A Quantitative Assay for Lycopene That Utilizes Reduced Volumes of Organic Solvents. J. Food Compos. Anal. 2002, 15, 309-317. [CrossRef] 